\title{
Overview about project planning
}

\author{
Cătălin Drob, Ph.D, „Vasile Alecsandri” University of Bacau, Romania
}

\begin{abstract}
The purpose of this article is to present the main aspects regarding project planning. This study is generally based on the fourth edition of the Guide to the Project Management Body of Knowledge (PMBOK Guide) developed by the Project Management Institute (PMI) in 2008. According to this edition of $\mathrm{PMBOK}$, project planning involves a group of processes required to establish the scope of the project, refine the objectives, and define the actions that must be undertaken to attain the objectives of the project.
\end{abstract}

\section{Keywords:}

Project, management, objectives, plan, schedule.

\section{JEL Codes: 021, 022}

\section{Introduction}

In accordance with the Guide to the Project Management Body of Knowledge (PMBOK Guide) elaborated by the Institute of Project Management (PMI), a project is a temporary endeavor undertaken to create a unique product, service, or result ${ }^{1}$.

Generally, a project can be characterized through five basic phases:

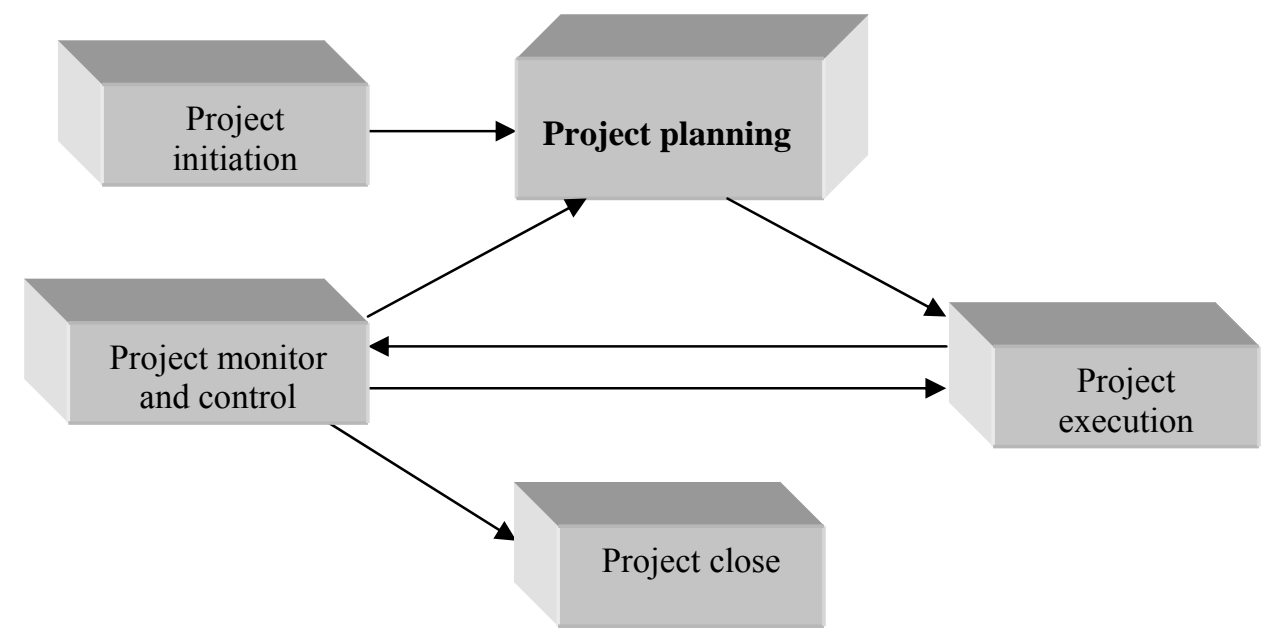

Figure. 1. The basic phases of project management

Source: Adapted from PMI (2008), Guide to the Project Management Body of Knowledge, Fourth Edition, p. 40

${ }^{1}$ PMI (2008), Guide to the Project Management Body of Knowledge, Fourth Edition, Project Management Institute, Inc., USA, p. 1 
Mainly, the initiation phase defines the problem that must to be resolved through the project, defines the objectives, requirements and overall project deliverables and identify the main risks of the project.

The starting point in the planning phase are results of the initiation phase, materialized into a document named Project Charter.

\section{Project planning}

Planning is considered by many specialists the most important task of the project management. The main components of the planning phase are the following ${ }^{2}$ :

- objectives, that must be accomplished in a given period of time;

- the program, that involves define the strategy and the main actions to be undertaken in order to achieve objectives;

- the schedule, that is a working plan that shows when activities will be started and finished;

- the budget, that shows expenditures that will be made for achieving the objectives;

- the forecast, which prefigures the future status of the project;

- the organization, which refers both to establish the component of the project team and the duties and responsibilities that will be assigned to project team members;

- the policy, that provides a framework, a general guide for conducting project activities;

- the procedure, that specifies the chronological sequences in which an activity or an action must be undertaken;

- the standard, which is a level of performance, unanimous regarded as appropriate or acceptable.

During the planning phase, starting from Project Charter it can proceed to elaborate another important document of the project called Project Scope Statement. This document presents, in detail, the description of the activities to be undertaken under the project, in order to obtain a product or service that meets the requirements requested by the client ${ }^{3}$.

Also, the Scope Statement should include the information about:

- project description and justification;

- project objectives/deliverables (the products, services, or results that the project will produce);

- product scope description (the characteristics, features and functions of the products, services, and/or results that the project will produce);

- product acceptance criteria (the criteria used for accepting products, services, or other project results);

- project constraints;

- main project assumptions etc.

After performing the Project Scope Statement the next phase of the project planning is to design the Work Breakdown Structure (WBS). The WBS is used for dividing the project into easily manageable components. The lowest level of the WBS is named work package. The work package (WP) represents a basic work sub-division of the project that is small enough so that the responsibility for its performing to be assigned to one person.

The WBS can be structured into different forms, using the phases of the project life cycle (as shown in the following figure), using major deliverables or using subprojects as the first level of decomposition:

\footnotetext{
2 Kerzner, H. (2001) Project management: A systems approach to planning, scheduling and controlling, Seventh Edition, John Wiley \& Sons, Inc.,USA, p. 552.

${ }^{3}$ Desmond, C.L. (2004), Project management for telecommunications managers, Kluwer Academic Publishers, USA., p. 36.
} 


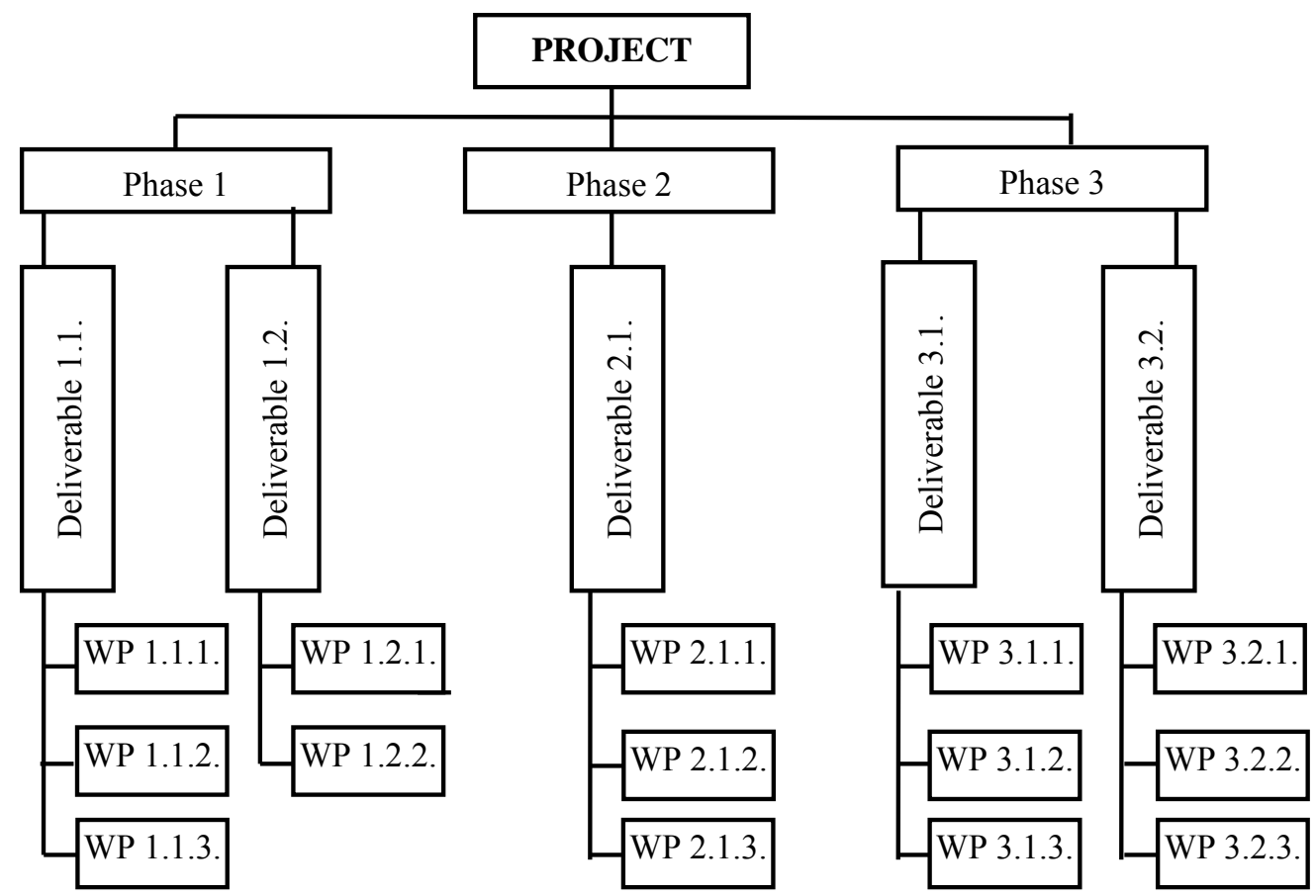

Figure. 2. Example of WBS elaborated using phases of the project life cycle as the first level of decomposition

Source: Adapted from PMI (2008), Guide to the Project Management Body of Knowledge, Fourth Edition, p. 120

Usually, the Work Breakdown Structure is a deliverable-oriented, hierarchical decomposition of the work to be completed during the project.

Starting of the WBS, the next steps in project planning involve define and sequence activities and estimate their resources and durations.

Define activities involves the identification of the actions that must be undertaken to produce the project deliverables. For this is necessary to decompose the work packages of the project are into smaller components named activities. The result of the define activities process is the activities list. This list includes all schedule activities that are planned to be undertaken on the project.

Sequence activities involve the identification of the logic relationships among activities. Sequencing can be performed by using different tools and techniques, such as: Precedence Diagramming method (PDM method), dependency determination, schedule network templates etc.

Estimate activity resources involve estimating what type and quantity of resources (material, people, equipment etc.) are necessary to perform every activity of the project. This step is considerate critical because it determine the budget of the project. The most used and accurate method for estimating activity resources is based on the Work Breakdown Structure and is known as the bottom-up estimating method. The main result of the estimating activity resources process is the list of requirements for each activity of the project.

Estimate activity durations is also considerate critical step because the accuracy of the project schedule (that represents next step in the project planning) depends on the accuracy of these estimates. The most used tools to estimate the activities duration are: analogous estimating, parametric estimating and three point estimates.

Analogous estimating is based on historical information about durations of a previous, similar activities undertaken in other similar projects. 
Parametric estimating considerate that activity duration can be estimated by multiplying the quantity of work by the productivity rate.

Three point estimates tool is relative similar with PERT (Program evaluation and review technique). Both methods involve the estimation of three activity durations: most likely, optimistic and pessimistic. The method considers that the duration of an activity can be estimated as an average of the three estimated durations.

The next step in project planning consists in the developing schedule of the project. Develop Schedule is the process that merges all of the work tasks to be performed, their relationships, their estimated durations, and their assigned resources to a calendar ${ }^{4}$. The project schedule can be presented in summary form or in graphical form (as milestone charts, bar charts or project schedule network diagrams). The schedule provides a basis for monitoring and controlling project activities and for tracking project progress.

The next step in project planning refers on developing budget. The budget of the project is the amount of money available to the project team to achieve objectives under the requirements specified by the client. For the determination of the budget, the first step consists in the identification and estimation of the activities cost. After this step, for developing a document called the project budget is necessary to aggregate the individual costs originally estimated.

In practice, for determining the budget can be applied some tools and technique, also used in estimating costs, such as reserve analysis. Other techniques used for determining budget are: cost aggregation, expert judgment, funding limit reconciliation etc. For example, cost aggregation is used to determine total costs for an entire project starting from estimated cost of the work packages at the lowest level of the WBS until the higher component levels of the WBS.

The last step in project planning consists in the developing the supporting plans, such as: quality plan, human resource plan, communications plan, risk management plan, procurements plan.

The most important result of project planning is a document called the project management plan. This plan describes how the project is executed, monitored, controlled and completed. The supporting plans can be considered as sub-plans of the project management plan.

\section{Conclusion}

Many authors are agreed that project planning is the key element for project success. There are some theories and standards regarding project management that have proposed different approach regarding project planning. For example, the Project Management Institute (PMI) has proposed a set of standards and practical guidance for project management, in a document known as the PMBOK (Project Management Body Of Knowledge). The fourth edition of this guide (standard), elaborated in 2008, consider that the project planning refers to the following processes: Develop Project Management Plan; Collect Requirements; Define Scope; Create Work Breakdown Structure; Define Activities; Sequence Activities; Estimate Activity Resources; Estimate Activity Durations; Develop Schedule; Estimate Costs; Determine Budget; Plan Quality; Develop Human Resource Plan; Plan Communications; Plan Risk Management; Identify Risks; Perform Qualitative Risk Analysis; Perform Quantitative Risk Analysis; Plan Risk Responses and Plan Procurements. In this article I tried to present the project planning steps based on the approach proposed by the PMI. In fact, the project planning is relative easy to define in theory, but in practice is more difficult to realize.

\footnotetext{
${ }^{4}$ Horine, G.M. (2005), Absolute Beginner's Guide to Project Management, Que Publishing, USA, 2005 , p. 54.
} 


\section{References}

1. Desmond, C.L. (2004), Project management for telecommunications managers, Kluwer Academic Publishers, U.S.A.

2. Drob, C. (2010), Management de proiect, Editura Alma Mater, Bacau

3. Horine, G.M. (2005), Absolute Beginner's Guide to Project Management, Que Publishing, U.S.A.

4. Lewis, J.P. (2007), Fundamentals of project management, Third Edition, AMACOM Books, U.S.A.

5. PMI (2008), Guide to the Project Management Body of Knowledge, Fourth Edition, Project Management Institute, Inc., U.S.A.

6. Verzuh, E. (2003), The portable MBA in project management, John Wiley \& Sons, Inc., U.S.A. 